The University of San Francisco

USF Scholarship: a digital repository @ Gleeson Library | Geschke Center

Nursing and Health Professions Faculty Research

and Publications

School of Nursing and Health Professions

2011

\title{
Transmen: The HIV Risk of Gay Identity
}

Stefan Rowniak

University of San Francisco, srrowniak@usfca.edu

C Chesla

C D. Rose

W L. Holzemer

Follow this and additional works at: http://repository.usfca.edu/nursing_fac

Part of the Gender and Sexuality Commons, and the Public Health Commons

\section{Recommended Citation}

Rowniak S, Chesla C, Rose CD, Holzemer WL. Transmen: The HIV risk of gay identity. AIDS Educ Prev. 2011 Dec;23(6):508-20.

This Article is brought to you for free and open access by the School of Nursing and Health Professions at USF Scholarship: a digital repository @ Gleeson Library | Geschke Center. It has been accepted for inclusion in Nursing and Health Professions Faculty Research and Publications by an authorized administrator of USF Scholarship: a digital repository @ Gleeson Library | Geschke Center. For more information, please contact repository@usfca.edu. 


\title{
TRANSMEN: \\ THE HIV RISK OF GAY IDENTITY
}

\author{
Stefan Rowniak, Catherine Chesla, Carol Dawson Rose, \\ and William L. Holzemer
}

\begin{abstract}
Many female-to-male transgender individuals, or transmen, are situated within the gay community, one of the highest risk communities for HIV, yet there has been little research regarding the experience of risk for these transmen. Seventeen transmen were interviewed regarding their sexuality and HIV risk behavior. Fourteen of the 17 reported having non-trans gay men as sexual partners. Risk behaviors included not using condoms with multiple partners who were HIV-positive, or of unknown HIV status. Aspects of risk included the unfamiliarity of the gay community and the lack of safe sex negotiating skills. The dynamics of acceptance and rejection between transmen and non-trans gay men impacted risk by compromising safety. Incorrect assumptions regarding transmen, non-trans gay men, and risk included beliefs that neither person could be at risk. Other aspects included the impact of testosterone on sexual behavior, the changed bodies of transmen, and sex work.
\end{abstract}

Many female-to-male (FTM) transgender persons, or transmen, are at high risk for HIV infection. This has been overshadowed to a great extent by the HIV risk and prevalence among male-to-female (MTF) transgender persons, or transwomen. However, there has been some recognition that many transmen identify with the gay community and have non-trans gay men as sex partners (Clements-Nolle, Marx, Guzman, \& Katz, 2001; Herbst et al., 2008; Sevelius, 2009). The San Francisco Department of Public Health recently included TMSM (transmen who have sex with non-trans men) within the larger HIV risk group MSM. HIV prevalence among MSM in San Francisco was recently estimated to be $24.3 \%$ (Scheer et al., 2008), and HIV was characterized as being hyperendemic in the gay community. The Centers for Disease Control and Prevention reported at the 2010 National STD Prevention Conference that gay men are 44 times more likely to acquire HIV than other men (Roehr, 2010). It is unknown if these statistics apply equally to transmen. This study was conducted in order to understand and explicate the situated HIV risk of transmen who identify as gay.

Stefan Rowniak is an assistant professor in the School of Nursing and Health Professions, University of San Francisco, San Francisco. Catherine Chesla and Carol Dawson Rose are professors in the School of Nursing, University of California, San Francisco. William L. Holzemer is the dean of the School of Nursing, Rutgers, New Brunswick, NJ.

Address correspondence to Stefan Rowniak, 769 14 $4^{\text {th }}$ St., San Francisco, CA 94114; e-mail: srrowniak@ usfca.edu 
A number of researchers have examined the HIV prevalence among transwomen and several recent articles have reported on the HIV risks of transgender persons in general (Herbst et al., 2008). However, the data regarding HIV prevalence and risk among transmen is sparse. One study conducted in San Francisco with 392 transwomen and 123 transmen (Clements-Nolle et al., 2001) found HIV prevalence for transwomen to be $35 \%$ and for transmen $2 \%$. An analysis of factors that were independently associated with HIV prevalence was conducted for transwomen but not for transmen because of the low prevalence. However, it was noted that $50 \%$ of the transmen in this study identified as gay or bisexual men, over $60 \%$ of all the transmen reported previous unprotected vaginal sex with a non-trans male, and $27 \%$ reported unprotected anal sex with a non-trans male partner.

Herbst and colleagues (2008) conducted a meta-analysis of studies involving HIV prevalence and risk among transgender persons in the United States conducted from 1990 through 2003. Of the 29 studies cited, the majority of the data concerned transwomen and only five studies had separate data concerning transmen. HIV prevalence rates for transmen were reported to range from $0 \%$ to $3 \%$. The authors of the meta-analysis concluded that although there were definite HIV risks reported for transmen, there were very few data as to the nature of those risks. Specific areas that were suggested for investigation included the effects of hormone use on sexual risk and the exploration of the social networks of sex partners (Herbst et al., 2008).

Researchers in one study reported transmen were more likely than transwomen to engage in high risk sexual activity and had less AIDS knowledge (Kenagy \& Hsieh, 2005). The researchers used a needs assessment survey of 122 transwomen and 62 transmen recruited from Philadelphia and Chicago. The researchers found that the majority of the transmen $(58.1 \%)$, identified as gay men, and $81 \%$ reported high-risk sex within the 3 months prior to the study compared with $55 \%$ of the transwomen. The study demonstrated that low HIV prevalence rates did not necessarily mean that the population of transmen was low risk and that is was possible, given the risk, for the prevalence to increase over time. The results supported the findings of an earlier study (Namaste, 1999). The data for the study came from interviews with five transmen and one discussion group of unknown size. Five areas of HIV concern were identified for transmen: (a) lack of information concerning transgendered bodies and sexuality, (b) denial of risk among many transmen, (c) poor access to clean needles for testosterone injections, (d) low self-esteem believed to result in a reluctance for transmen to adopt safe sex practices, and (e) the exclusion of transmen from many social service agencies.

Using focus groups and survey methods, Sevelius (2009) examined the HIV risks specific to 45 transmen who had sex with non-trans men and how they perceived the impact of gender identity and gender expression on sexual decisionmaking. A majority reported inconsistent condom use for receptive vaginal and anal sex. The factors of unequal power dynamics, low self-esteem, and a need for gender identity affirmation contributed to sexual risk. Despite the high-risk activity documented, transmen still had a reported low HIV prevalence of $2.2 \%$. This, in part, was attributed to such protective strategies as online meeting that could allow for both disclosure and safe sex negotiation prior to an actual face-to-face encounter.

In summary, there are transmen who are definitely at risk for HIV and other STDs. These are TMSM, or transmen who have sex with men, a subset of the larger transmale population that, like all populations, has variability in sexual behavior. A low prevalence may not reflect a change in risk for a population, such as entering the gay community. Data are lacking on the actual number of transmen who identify as 
gay. However, the recent increase in the number of clinics that offer gender transition services in addition to reports in the gay press of transmen becoming a noteworthy presence at various gay men's events (Brogan, 2010) seem to indicate that transmen are increasing their visibility within the gay community. As integration into the community increases, so may HIV incidence. It is also possible that there has been underreporting or misreporting of transmen as simply transgender and thus interpreted to be transwomen. A high percentage of the transmen involved in the studies reported gay non-trans men as sex partners and many identified as being gay. There is a lack of information regarding how transitioning from a variety of other communities into the gay community impacts risk. This study will provide insight from the perspective of the transmen participants. It will examine the situated risk of transmen and provide knowledge and an understanding of how they maneuver and adapt to the gay community and the unique risks that result from their transition.

\section{METHOD}

The design of this study was guided by interpretive phenomenology (Benner, 1994; Chan, Brykczynski, Malone, \& Benner, 2010; Leonard, 1994), an inductive, interpretive method. We employed the methods of interpretive phenomenology to analyze interviews with the participants. A phenomenological approach is particularly well suited to understanding the lived experience of transmen, their sexuality, the gay community, the associated risks, and the actions taken to engage in or reduce risk. The object of phenomenology is experience. This refers to a study participants' actions and concerns relevant to the subject of interest. It is through their engaged practical activities that experience is understood and interpreted. Sexuality within the transgendered body can be seen as lived experience whose meaning can be found in both the language of research participants as well as their embodied habits and practices. Also, of primary importance, is understanding the situatedness of participants and how this opens up possibility for some action but constrains other action. The situation for these participants is one of finding themselves in a new community with new norms and much more dangerous consequences. This directly impacts their concerns and subsequent actions with regard to sexuality.

There were two distinct phases of the study. The first phase consisted of semistructured interviews with six participants. This was to gain an initial understanding of the population and the parameters of the experience being explored. In phase two an additional 11 participants were recruited for a total of 17 participants. The additional participants had an initial in-depth interview of approximately $1 \frac{1}{2}-3$ hours in length and a follow-up interview several weeks later. The follow-up interviews were focused on clarifying specific statements made by the participants and were 30-90 minutes in length. It was determined that after the 17 th participant no additional information relevant to the study was occurring and recruitment stopped. Data were collected from September 2009 until May 2010.

The participants constituted a convenience sample. It was anticipated that this might be a difficult population to access so a variety of different locations were chosen for recruitment. A local community-based organization that provides counseling and social services for transgender persons in San Francisco referred several participants. Two medical clinics that provide transgender services in San Francisco referred several others. Flyers were also placed in the Lesbian, Gay, Bisexual, and Transgender Community Center in San Francisco and at a sex club in the city known 
to cater to transmen. The sex club was chosen because it served as the location of various community meetings for transmen and representatives of community-based organizations. Participants also referred several participants in a snowball fashion.

Inclusion criteria included being at least 21 years of age, identifying as a femaleto-male transgender person, taking testosterone for at least one year, and understanding English. There were no specific exclusion criteria. The participants ranged in age from 23 to 64 with a median and average age of 36 . The participants were asked to state their race or ethnicity. Ten of the participants self-identified as White and the seven others self-identified as White/Hispanic, Hispanic/Native American, Hispanic, African American/Hispanic/White, White/Basque, Jewish, and mixed race. The number of years taking testosterone ranged from one to 15 with a median of two years. None of the participants had phalloplasty, or bottom surgery. Participants were compensated for their time with a $\$ 20$ gift certificate for the first interview and a $\$ 10$ certificate for the second interview. All participants signed an informed consent prior to being interviewed. The names used here are pseudonyms to protect the identity of the participants. The study received approval from the University of California, San Francisco, Committee on Human Research, H642-32870-02A.

The analysis of the data was an ongoing process that began with the first interview and continued throughout the entire study. The primary researcher wrote an interpretive memo within 24 hours of each interview. This addressed initial impressions relevant to the emerging lines of inquiry. All interviews were recorded and transcribed. All transcripts were coded for emerging themes and categories using the ATLAS.ti computer program. This program provided the basis for the development of preliminary codes that were then consolidated into the final themes. The process of member checking, whereby both participants and nonparticipant members of the transmale community in San Francisco were asked to provide feedback, confirmed these themes. In addition, a medical provider with an extensive history of working at the Department of Public Health transgender clinic provided input.

\section{RESULTS}

The participants not only transitioned with regard to their gender presentation, but for some, sexual behavior and orientation also changed. Prior to their transition, seven participants were lesbian identified. Three identified as heterosexual and seven as bisexual or queer. After transition, 14 stated that they had gay men as sexual partners and identified as gay, bisexual, or queer. This included four transmen who had been lesbian identified. Only three participants who identified as lesbian prior to transition retained a primary sexual attraction toward women. This discussion of HIV risk is limited to the data from the 14 who reported having sex with non-trans gay male partners.

Self-reports regarding HIV status were obtained from all of the participants. All tested for HIV on a regular basis. Sixteen reported that they were HIV-negative. One participant reported receiving a positive result approximately 6 months prior to his interview. He stated all the anal and vaginal intercourse he engaged in was protected and was he uncertain how infection occurred. However, he also engaged in S\&M activities involving blood play, a possible route of infection. Two had hepatitis C, likely contracted through needle sharing.

Twelve of the 14 participants, whether they identified as gay, bisexual, or queer, stated that they had ongoing multiple partners. Four were in nonmonogamous re- 
lationships allowing additional sexual partners. One participant had been with his boyfriend for almost 1 year; they were moving in together at the time of the second interview. Other relationships were of shorter duration and several had ended by the time of second interview. Only 3 participants reported always using condoms for intercourse while 11 did not despite knowing about the risk of HIV. Two participants had steady boyfriends who were HIV-positive and two other participants knew that some casual sex partners were HIV-positive. Most did not know the status of their casual sex partners.

Several themes were identified specific to the experience of transmen situated within the gay community that impacted how sex and safety were negotiated. These themes were not mutually exclusive but operated concurrently to create an increased vulnerability. We first discuss the unfamiliarity many had with the social/sexual workings of the gay community. Next we examine dynamics between gay non-trans gay men and transmen that resulted in an increased risk for some. These included the need for validation coupled with the difficulty of disclosure, and the dynamics of acceptance and rejection between the transman and biologically normative gay man. That is followed by a discussion of several assumptions made by both non-trans men and transmen regarding risk. Testosterone also impacted risk in several ways that will be discussed. Finally, sex work emerged as a significant risk factor for a subset of participants.

\title{
AN UNFAMILIAR COMMUNITY
}

Transition into the gay community was often completely unanticipated. Many participants were ill prepared for living as gay men within a gay social world and were trying to understand the rules and codes of sexual behavior and how to negotiate safety. For those who had little or no experience with the gay, lesbian, or queer communities, the transition was most problematic. Three had been married to heterosexual men, and some, like Ricardo, experienced limited contact with gay men. He found transitioning presented risks he never had to consider before

\begin{abstract}
See, I never had to think about it before, I was married, I was heterosexual. I didn't have sex much before marriage. I was asexual for a long time. And then when I was promiscuous, it was pretty protected, but then I was married, and you don't have to worry about it. So this was really the first time I'm really afraid, or you know, have concern, about getting it. And so I think I can be lackadaisical about that. Because I wasn't around when the whole AIDS thing happened. I knew about it but I wasn't involved, or didn't know people. It didn't impact upon my life. I knew one guy at work that died of it, but, it was just kinda "Oh, that's what gay men do," you know. Never dreaming I'd be one.
\end{abstract}

Ricardo's familiarity and experience was with a heterosexual social world and he found himself a gay man at age 45 . Four of the participants had been lesbian-identified prior to becoming gay men, and like Ricardo, the idea of needing to protect themselves from the possibilities of HIV or STDs was not a part of their previous experience. It was an abstract notion that had never impacted their lives before. Ben, who worked at a sex club that catered to both non-trans gay men and transmen, commented about the risk he sometimes saw transmen engaged in

I know quite a few guys that definitely don't want to talk about it, either because they don't want to be like standing out, but they don't know that much about having sex with guys, and what's okay, what's not okay. And that are just happy to have sex with guys, no matter what. And they don't really know much about safe sex, or educate themselves because they don't want to be outed as not knowing so much. I see that. 
Even familiarity with gay men did not necessarily impart the practical knowledge of how to successfully maneuver through the social and sexual territory of the gay community. LeRoy was a fully passing sexually active gay man within 2 or 3 months of transitioning in his mid-20s, but his inexperience in being a part of the gay community led to situations of risk

I think there are things that gay men, that we deal with that-and it takes a while. But after a while, you get tired. You get tired of using condoms. You start to realize that every other person you talk to has HIV. There's a lot of substance use. I don't think I was prepared for that, no.

LeRoy was initially unprepared for the reality of gay sexuality. This led at times to risk taking that would have been unacceptable to him prior to transition.

\section{DYNAMICS OF ACCEPTANCE AND REJECTION}

All of the transmen in this study expressed a need for validation of their male identities. Their previous lives and identities as women were gone and the new identity required reinforcement and feedback. For the majority who identified as gay men, an important source of validation came from the sexual attention of gay men. However, the phallocentric attitude that they encountered throughout much of the gay community made acceptance of a man without a penis a major challenge. Passing conferred social acceptance in gay society, often with an accompanying invisibility with regard to ones transgender status. However, passing was no guarantee, on the interpersonal level, of success in finding sexual partners or in finding sexual partners who would become longtime partners. The point at which, in the course of transition, the participants passed as male was different in each circumstance based upon, among other things, the person's genetics and dosage of testosterone (Gorton, Buth, \& Spade, 2005).

It was early in transition that the question of whether or not one passed was most uncertain. That determination came from the response of others to one's gender presentation. Some participants reported difficulty in knowing how others perceived them, or where to locate themselves apropos of gender. Carl told of a man he met on the Internet for sex whose perception was that he was a pretty 14-year-old boy when in reality he was 24 years old. Despite the fact that this perception was far from affirming the identity Carl was striving for, the feedback he received helped him to understand how others were reading him. He eventually felt the need to be perceived as older, which reinforced his continued use of testosterone as he carried on with his transition.

At times, need for validation compromised sexual safety. Many participants reported situations when desire for validation through sex with a gay man led them to forgo the condom they intended to use. For many, this validation trumped all other considerations. Ricardo, who was just 1 year into his transition, spoke of how important validation was and how achieving it put him at risk.

I'm still in that learning phase of who I'm attracted to. And I have to say that the men I've been with I was wanting more sexual validation than really attracted to them. But the sexual validation really takes priority sometimes. I'm learning that, "hmm, I'm compromising myself." I'm learning to say that, am I compromising myself just to get validation sexually, or you know, is there an attraction there. 
All 14 who had non-trans men as sexual partners stated that validation of identity and the feeling of belonging in the gay community were things that mattered to them. Two transmen reported willful actions of intentional risk in order to become more integrated into the gay community. They reported that this desire was so overwhelming that at one point in their posttransition lives they tried to become HIV-positive so that they could feel an even greater affinity with the community. As Cheyenne recounted:

\begin{abstract}
And there was something that happened one time, I felt like everybody around me was positive. I don't know, it just was like my experience at the time, it's not necessarily my experience right now. But at the time I felt I was already different and already left out, and I know I'm not the only one that felt that way. It felt like I already had a disease with my blood that could put people at risk, you know, with having hepatitis. But it wasn't really giving me a sense of belonging, or giving me free acupuncture, free massage, free reiki, free housing, free this and that. Although now there's not so much of that. But I was getting off on putting myself at risk, you know. And I was even telling people I was positive so they wouldn't have issues about being with me sexually.
\end{abstract}

The desire for validation through sex was complicated by the dilemma of when to disclose one's transgender status. Participants varied regarding when disclosure should take place or how to do it. All agreed disclosure was an awkward social negotiation that they fumbled through. They stated that if there was going to be a sexual encounter, then disclosure would be appropriate; however, many told of situations where disclosure did not take place. For example, it was possible to perform oral sex, keep their pants on, and not disclose their transgender status.

Although the avoidance of disclosure was initially the easiest solution, there was always the danger of discovery that presented the risk of not just rejection but possible violence. None of the participants reported violence resulting from discovery, but they were always aware of the potential. The right timing was essential for disclosure. Keith related his own idea regarding when that should be:

Actually, I usually don't disclose that I'm trans unless I'm about to get into somebody's pants. Or think that I'm going to. It depends. If I'm just at a sex club, then I wear a jockstrap, I don't disclose. I don't feel that it's really relevant. If it looks like there's dating potential, or whatever, then it's a conversation that's had, and that's actually before it gets physical. But if it seems like there definitely is interest, and usually it's not the first conversation, but a second conversation or what have you.

Another option was disclosing up front so there was no doubt as to the transman's status. This immediate disclosure was employed in two ways that many of the transmen used to meet their partners. The first was via the Internet. Personal ads and profiles were an acceptable means for disclosure that could reduce emotional repercussions. All of the participants, with the exception of one who did not own a computer, reported that they used this method for casual hooking up and stated that they were able to disclose their status in this manner. However, even this impersonal method was not completely without risk. Some told of mean-spirited postings on their profiles from gay men. The other way to disclose up front was the nonverbal method. This meant exposing their status right from the start and was done in sex clubs where the patrons checked their clothes.

Besides the need for validation, the dynamic between trans and non-trans men also impacted safety. This dynamic involved the perceived acceptance or rejection of the nonnormative body of the transman. Sam, who in his life was both a female and 
transmale sex worker, offered this explanation for what he referred to as power positioning. This was where a transman might believe that his transgender body would entitle his non-trans male partner to not use a condom:

I think that there is this dynamic of a lot of trans guys enter gay men's worlds, like post transition. And it's something that they are going into very rapidly, and without maybe some of the understandings of like, what's expected, or like, what are sexual health practices and all these things. And they're also coming at it from this position of insecurity of identity. And I've definitely heard people say, like, I have a friend who I'm talking to at the moment about his unsafe sex practices. And he says he'll go home with a guy and then he'll put a condom on and they get soft. And he's worried that the reason they're getting soft is because he's trans. And then he feels like he has a debt to let them not use a condom because of his nonnormative body. It's more about the emotional reasons that people don't use condoms when they're trans.

Several of the participants spoke about feeling guilty if their partner had erectile dysfunction and as a result of feeling guilty, did not use a condom for sex. The dysfunction was interpreted as a lack of sexual desire for the transman and not as something that can occur regardless of desire or intent. This personalization of the dysfunction was, in part, due to the unfamiliarity with gay men as sexual partners.

\section{ASSUMPTIONS REGARDING TRANSMEN, THEIR PARTNERS, AND RISK}

Safety in a sexual encounter also depended upon the fact that both individuals understood the risk involved and had agreed on a plan for reducing it. Therefore, another important aspect of risk was assumptions held by both the transman and his non-trans partner. Just as some transmen lacked the skills necessary to negotiate safety with non-trans gay men, participants reported that some gay men lacked information regarding risk with, and to, transmen.

Participants who had sex with non-trans gay men were usually the bottom, or the receptive role, for anal or vaginal sex. Some preferred vaginal, or frontal sex, others anal, and some enjoyed both for different reasons. Many participants stated that they would have been content to have nonpenetrative sex but often vaginal or anal sex was all their partner wanted. As Hank said:

Once gay men understand that you have female anatomy, they feel like it's less risky for them. That maybe they don't need a condom for whatever they're doing, for whatever both of you are doing. Or that because their risk is lessened by being with, I don't know if it's the perception of somebody who hasn't been a gay man for quite as long, or just that those body parts don't transmit AIDS and STDs [sexually transmitted diseases] in the same way. I talked to a few people who have had a similar experience as bottoms. To say that the person on the receiving end, whether it's anal or vaginal sex, isn't going to transmit anything to the top, and if the top's clean, then it's all safe. Which of course isn't the case, but I mean, statistically there's probably something to that.

Transmen also spoke of assumptions that they made that led them to justify forgoing condoms in certain encounters. Keith reported that before he believed that he was passing well, he assumed that the men who were attracted to him were straight or perhaps bisexual. He went on to assume that they also would not pose a risk for HIV.

And what I noticed was that when I was looking for men on Internet site, very few gay men would respond to me, it was mostly straight men and bi men. And I think this was 
because I was being perceived as some butch dyke. I just assumed that if somebody was interested in me, because I was F-to-M, it meant that they were straight, or bi, but really they were primarily attracted to women. They were also into F-to-Ms, but didn't really have that much F-to-M experience. So I did have this assumption that is now being challenged, that men who are attracted to me were actually not gay. And I think perhaps because of that there were some times where it felt easier to take certain risks.

Keith pointed out that these assumptions were made early in transition when he was unsure of how well he was passing. If a man were attracted to him, then that man could not be a gay man, and therefore that man was lower risk than a gay man and the need for safety in sex was less of an imperative.

Sometimes assumptions were based on fragments of factual information that were used to defend rather unsafe practices. For example, receptive anal intercourse is the primary risk for gay men, but that does not mean that vaginal sex is a safe activity. However, as Keith recounted, that very assumption was common, "I was using the front a lot, because you know, you don't have to clean, it's just easier, there was also this level of like, okay, I'm not at risk because the higher risk is the anal."

\section{TESTOSTERONE AND CHANGED BODIES}

Although the gay community was often unfamiliar territory, transition with testosterone also brought about a changed body that could be just as unfamiliar and a source of concern with regard to sex and safety. Also, access to testosterone was problematic for some. In San Francisco testosterone is fairly easy to access through several low cost transgender clinics. However, some participants, such as Ski, began their transition outside San Francisco and had to buy testosterone and needles on the black market.

Testosterone use resulted in a number of reversible and irreversible changes. These ranged from increased libido, acne, emotional changes, and increased appetite, to physical changes such as increased facial and body hair, increased muscle mass, and clitoromegaly. Genital changes most concerned the participants with regard to safety. Some reported that they experienced vaginal dryness predisposing them to bleeding during intercourse, thus increasing any possible risk. Mick, the only participant who was HIV-positive, was worried about whether the rules of safety would be changed with his changed genitals.

I'm trying to get statistics from anybody. I'm in the middle of writing this freaking thing on HIV prevention modules, I can't get a good answer from anybody on whether there's any good way for trans guys to have their cock sucked unless you're using a dental dam in which case it doesn't work the same way as it's working on a female body. Because when my clit was only this big, licking or even light sucking, that makes sense. But when I got this much, like that's-that doesn't make sense for a dental dam anymore. There's no devices out there on the market other than wearing slightly baggy latex hot pants. That's about it. That's what we got. And so, yeah, a lot of options have been taken away from me.

Mick was concerned that the large size of his transformed clitoris and its close proximity to infectious vaginal fluids would present a greater risk than he was willing to subject his partners to. He was also frustrated that he could get no information specific to trans bodies and risk.

Universally, participants reported that the use of testosterone resulted in a second adolescence period characterized by a remarkable hypersexuality. Some stated this period lasted for only a few months while others claimed that it lasted for more 
than a year. Although all experienced the feeling of hypersexuality, not all acted on it. However, several participants believed that the use of testosterone contributed to situations of hooking up with men and agreeing not to use condoms.

\section{SEX WORK}

Five participants disclosed that they had been involved in sex work. Three were engaged in sex work before and during transition and the other two began the work after transition. Especially for those who began after transition, part of the motivation was to see if they passed well enough to attract gay men as clients. Another motivation was to earn money to pay for top surgery not covered by health plans. Four of the five reported always using condoms with their clients. Sam, who had been doing sex work for more than 7 years and was still engaged in it, made the comment that even though he could and did demand condom use from his clients, this was not necessarily an easy thing to do and it required experience and assertiveness.

LeRoy became a sex worker for about a year shortly after he transitioned. The reason he stated for doing this was his dire economic situation at the time. He also admitted he romanticized the idea of being a sex worker. He reported that he used condoms with all of his clients except one whom he knew to be HIV-positive. He described how this came about:

It just started out, like, we didn't use condoms. There was a lot of power dynamics happening there, which is like, he's a biological man; I'm a trans guy. He's HIV-positive; I'm HIV-negative. I'm a sex worker and he's paying me to have sex. So, I mean I think the biggest thing in there is the being paid to have sex. And there was-I don't know, I just was afraid to ask him to use a condom. I denied that it was as risky as it was, in my head, to make it okay.

Sex work was a new experience for LeRoy and he had not yet learned how to advocate for his safety needs. It was after seeing this client for 3 months that he gave up sex work completely.

\section{DISCUSSION}

Living in the gay social and sexual community meant that the participants found themselves in a milieu that posed a high risk for the acquisition of HIV infection. During the course of the HIV epidemic, phenomena such as safe sex fatigue and treatment optimism adversely impacted risk reduction messages of public health campaigns and led to an attitude of indifference with regard to safety among some gay men (Ostrow et al., 2008; Schwarcz et al., 2007). MSM also developed a number of strategies that may or may not be effective in reducing the chances of becoming infected while opting not to use condoms with their partners. These included such adaptations as serosorting, or choosing sex partners who presumably have the same HIV status (Osmond, Pollack, Paul, \& Catania, 2007; Rowniak, 2009; Truong et al., 2006), and strategic positioning, or taking the role of top in anal sex with the hope that transmission from the infected person on the bottom will not occur (Elford, 2006; Hart \& Elford, 2010).

The transmen participants demonstrated that they had adopted many of the same responses to HIV as the larger gay community. When LeRoy voiced the sentiment from his position as a member of the gay community that "you get tired of using condoms," he was echoing the same language of safe sex fatigue that had 
been attributed to non-trans gay men. The transmen who had HIV negative steady partners were engaging in the same strategy of serosorting as many in the larger gay community, whether it is actually protective or not. One important difference was that while non-trans gay men had the option of strategic positioning, this was not a possibility for most of the participants. Another phenomenon that has been reported is that of gay "bug chasers" who tried to become infected with HIV (Grov \& Parsons, 2006). That term could certainly be used to describe the behavior of the two transmen who stated that they engaged in high-risk behavior in order to become infected.

However, the circumstances of being a transman in the gay community also meant that there were unique aspects of risk specific to their situation. These included the unfamiliar nature of the gay community, the nature of the dynamics between non-trans gay men and transmen regarding gender validation or rejection, incorrect assumptions concerning safety and risk, the effects of testosterone on sex drive and the physical body, and a high proportion engaged in sex work.

These distinct aspects of risk, operating singly or synchronously, influenced HIV risk for transmen in the gay community. However, simply needing validation through sex, or the presence of any of the other risk factors, did not automatically mean that transmen compromised their safety. Various influences contributed to the specific vulnerability of the participants and allowed the risk to occur. For example, those earlier in their transition had less practical experience and were more likely to be overwhelmed by the new sexual possibilities available. Drugs and alcohol increased vulnerability in social and sexual situations. Depression or other psychological problems contributed to risk as the situation of the two transmen who sought infection suggested.

Those transmen who were earlier in their transition had less opportunity to learn how to adjust to the new community. They arrived with a newly activated sex drive but without the practical knowledge of how to negotiate their own safety. For many, not only was the gay community foreign, being a gay man operating within the gay community was completely unexpected. Those who identified as lesbian prior to transition anticipated continuing with women as partners, and those who had male partners were familiar with heterosexual men, not gay men and the culture of gay sexuality. However, negotiating gay sexuality could be learned over time, but learning entailed a period in which poor judgment and mistakes were possible.

Given the risk of being a gay man, especially in an urban center like San Francisco, it is puzzling why the reported HIV prevalence among transmen is so much lower than among non-trans gay men. There are several possibilities. It could certainly be that prevalence is much higher but that the testing locations are not capturing the fact that some of their clients are transmen. Many clinics still classify all transgender individuals into one category or classify transmen as females. Sevelius (2009) suggested that there might be protective strategies such as online hooking up that help to guarantee that safe sex guidelines will be followed. It is also possible that because the phenomenon of transmen in the gay community is still relatively new and numbers are increasing that the impact on new HIV infections has not yet been seen.

There were several limitations to this study. The finding from a small sample cannot be generalized to the general population of transmen in the United States. The majority of participants were transmen who had sex with men. It is possible that the sites of recruitment, such as the sex club and LGBT center, influenced the high levels of risk that were reported. However, these are locations that are commonly frequented by many members of the transgender community in San Francisco and 
hopefully did not skew the findings. Recruitment in a city other than San Francisco could result in a majority who identified as heterosexual and had non-trans females as partners. None of the participants had phalloplasty and perhaps the experience of transmen with phalloplasty within the gay community is very different. Also, all of these participants lived in an urban environment. The experience of those who live in a rural or suburban area could also be very different. A greater variety in racial and economic background of the participants would provide a broader understanding of the phenomenon. It would also be beneficial to understand the experience of the partners of transmen. Despite the fact that the reported HIV prevalence for transmen is very low, the results of this study suggest that the degree of sexual risk behavior among TMSM is comparable to that of non-trans gay men. It is also possible that being a transman within the gay community confers an even greater vulnerability than experienced by other members of the gay community. Transmen are still a relatively new phenomenon within the gay community. Without inclusion in risk reduction interventions aimed at the larger gay community as well as specifically focused interventions, transmen's HIV incidence could approach that of the rest of the community.

\section{REFERENCES}

Benner, P. (1994). The tradition and skill of interpretive phenomenology in studying health, illness, and caring practices. In P. Benner (Ed.), Interpretive phenomenology: Embodiment, caring, and ethics in health and illness (pp. 99-127). Thousand Oaks, CA: Sage.

Brogan, S. (2010). Trans man wins IML 2010. Bay Area Reporter Online, 40(25). Retrieved from http://www.ebar.com/arts/art_article. php? sec $=$ leather $\&$ article $=108$

Chan, G., Brykczynski, K., Malone, R., \& Benner, P. (2010). Interpretive phenomenology in bealth care research (1st ed.). Indianapolis, IN: Sigma Theta Tau International.

Clements-Nolle, K., Marx, R., Guzman, R., \& Katz, M. (2001). HIV prevalence, risk behaviors, health care use, and mental health status of transgender persons: Implications for public health intervention. American Journal of Public Health, 91(6), 915-921.

Elford, J. (2006). Changing patterns of sexual behaviour in the era of highly active antiretroviral therapy. Current Opinion in Infectious Diseases, 19(1), 26-32.

Gorton, R. N., Buth, J., \& Spade, D. (2005). Medical therapy and health maintenance for transgender men: A guide for health care providers. Retrieved April 16, 2010, from http://www.nickgorton.org

Grov, C., \& Parsons, J. T. (2006). Bug chasing and gift giving: The potential for HIV transmission among barebackers on the internet. AIDS Education and Prevention, 18(6), 490-503.
Hart, G. J., \& Elford, J. (2010). Sexual risk behaviour of men who have sex with men: emerging patterns and new challenges. Current Opinion in Infectious Diseases, 23(1), 39-44.

Herbst, J. H., Jacobs, E. D., Finlayson, T. J., McKleroy, V. S., Neumann, M. S., \& Crepaz, N. (2008). Estimating HIV prevalence and risk behaviors of transgender persons in the United States: A systematic review. AIDS and Behavior, 12(1), 1-17.

Kenagy, G. P., \& Hsieh, C. M. (2005). The risk less known: female-to-male transgender persons' vulnerability to HIV infection. AIDS Care, 17(2), 195-207.

Leonard, V., W. (1994). A Heideggerian phenomenological perspective on the concept of person. In P. Benner (Ed.), Interpretive phenomenology: Embodiment, caring, and ethics in health and illness. Thousand Oaks, CA: Sage.

Namaste, V. K. (1999). HIV/AIDS and female to male transsexuals and transvestities: Results from a needs assessment in Quebec. International Journal of Transgenderism. Retrieved March 30, 2008, from http:// www.symposion.com/ijt/ijtintro.htm

Osmond, D. H., Pollack, L. M., Paul, J. P., \& Catania, J. A. (2007). Changes in prevalence of $\mathrm{HIV}$ infection and sexual risk behavior in men who have sex with men in San Francisco: 1997 2002. American Journal of Public Health, 97(9), 1677-1683.

Ostrow, D. G., Silverberg, M. J., Cook, R. L., Chmiel, J. S., Johnson, L., Li, X. et al. (2008). Prospective study of attitudinal and 
relationship predictors of sexual risk in the multicenter AIDS cohort study. AIDS and Behavior, 12(1), 127-138.

Roehr, B. (2010). Gay men 44 times more likely to get HIV. Windy City Times, 1-2. Retrieved from http://www.windycitymediagroup.com/gay/lesbian/news/ARTICLE. php?AID $=25818$

Rowniak, S. (2009). Safe sex fatigue, treatment optimism, and serosorting: new challenges to HIV prevention among men who have sex with men. Journal of the Association of Nurses in AIDS Care, 20(1), 31-38.

Scheer, S., Kellogg, T., Klausner, J. D., Schwarcz, S., Colfax, G., Bernstein, K. et al. (2008). HIV is hyperendemic among men who have sex with men in San Francisco: 10-year trends in HIV incidence, HIV prevalence, sexually transmitted infections and sexual risk behaviour. Sexually Transmitted Infections, 84(6), 493-498.

Schwarcz, S., Scheer, S., McFarland, W., Katz, M., Valleroy, L., Chen, S. et al. (2007).
Prevalence of HIV infection and predictors of high-transmission sexual risk behaviors among men who have sex with men. American Journal of Public Health, 97(6), 1067-1075.

Sevelius, J. (2009). "There's no pamphlet for the kind of sex I have": HIV-related risk factors and protective behaviors among transgender men who have sex with non-transgender men. Journal of the Association of Nurses in AIDS Care, 20(5), 398-410.

Truong, H. M., Kellogg, T., Klausner, J. D., Katz, M. H., Dilley, J., Knapper, K. et al. (2006). Increases in sexually transmitted infections and sexual risk behaviour without a concurrent increase in HIV incidence among men who have sex with men in San Francisco: A suggestion of HIV serosorting? Sexually Transmitted Infections, 82(6), 461-466. 
Copyright of AIDS Education \& Prevention is the property of Guilford Publications Inc. and its content may not be copied or emailed to multiple sites or posted to a listserv without the copyright holder's express written permission. However, users may print, download, or email articles for individual use. 